\title{
Management of fibromyalgia
}

\author{
Simon Carette MD FRCPC
}

S Carette.

Management of fibromyalgia.

Pain Res Manage 1996;1(1):58-60.

This article reviews an approach to the management of patients with fibromyalgia, with particular emphasis on the principles of education and the active involvement of the patient in treatment.

Key Words: Chronic pain, Fibromyalgia, Management

\section{Prise en charge de la fibromyalgie}

RÉSUMÉ : Cet article examine une approche pour la prise en charge des patients atteints de fibromyalgie, en insistant particulièrement sur les principes d'éducation et sur la participation active du patient au traitement.
$F^{1 / 20}$ bromyalgia is a chronic pain syndrome characterized by diffuse musculoskeletal pain, nonrestorative sleep, fatigue, psychologic distress and the presence of numerous tender points at predetermined sites (1). The etiology and pathophysiology of fibromyalgia are poorly understood (2). The syndrome is seen more commonly in women (7:1) and its prevalence in the general population increases with age, with values reported as high as $7 \%$ between 60 and 79 years (3). Fibromyalgia constitutes the second most frequent cause of referrals to rheumatologists (4).

The management of patients with fibromyalgia is difficult and at times frustrating to both patient and physician. Complete remission is rarely seen and symptoms tend to persist with time in the majority of patients referred to tertiary care centres, independent of the treatment received (5-8). Patients from community-based practices may fare slightly better (9) (Table 1).

\section{EDUCATION}

It is not unusual for patients with fibromyalgia to have consulted numerous physicians and other health professionals before a diagnosis is finally made. Most patients will find relief when told that they suffer from a condition that is 'real' and frequent.

Despite the controversy that still surrounds the existence of fibromyalgia as a distinct entity $(10,11)$, there is no doubt that the symptoms reported by the vast majority of patients with this condition are real, whether one believes their underlying etiology to be primarily organic, psychologic or both. I believe that it is therapeutically important to make a clear statement to the patient to the effect that we recognize the genuineness of their symptoms. Not only does this help to create a relationship of confidence but also, in many instances, it dismisses any previous counterproductive suggestions that their symptoms "may be in their head'. It is also helpful for them to recognize that fibromyalgia is a frequent chronic pain condition $(3.4 \%$ for women and $0.5 \%$ for men in the general population [3]) and that they are not alone in this situation. Furthermore, while acknowledging that fibromyalgia can decrease the quality of life, it is crucial to reassure the patients that this condition will not lead to joint destruction and deformities, and it will not affect their survival.

It is essential to set realistic goals from the outset. The patient must understand that total 'cures' are very rare and that the vast majority will continue to remain symptomatic over the years. The treatment objective therefore should not be to become symptomfree but rather to gain a better control over the symptoms and to become more functional.

Most patients will ask their physician what causes fibromyalgia. The etiology of the syndrome is essentially unknown. No genetic predisposition has been described (12). While in some cases trauma, surgery and medical illnesses have been suggested as precipitating factors (13), the exact role of such events in the development of the syndrome remains speculative. 
The pathogenesis of fibromyalgia is also poorly understood. Abnormalities in sleep physiology, muscle metabolism, immune system, neurotransmitters and the hypothalamopituitary axis have been described but most, if not all, of these studies lacked appropriate controls (2). It remains to be described whether these abnormalities are causative of the syndrome or simply represent nonspecific markers. Until this is clarified practitioners should be extremely cautious when discussing some of these data with their patients in order to avoid raising false hopes and potentially creating a dependency on external solutions in some individuals.

While the cause and pathophysiology of fibromyalgia are unknown, there is much to suggest that many patients with fibromyalgia eventually become trapped in vicious cycles that perpetuate the symptoms (Figure 1). Chronic pain causes sleep disturbances, secondary fatigue and psychological distress. Eventually, many patients reduce their level of activity because of their symptoms and, in many cases, for fear of exacerbating their condition. These factors (insomnia, fatigue, frustration, depression, inactivity, self-depreciation) in turn tend to perpetuate the pain and the related symptoms. Explaining these vicious cycles to the patient in simple terms, followed by strategies to break the cycles, is the most important aspect of successful management of fibromyalgia.

\section{PAIN MANAGEMENT}

Obviously, it appears that the most logical way to break these vicious cycles is to get better control of the pain that is at the centre of the problem. Unfortunately, traditional pharmacological approaches used for the management of musculoskeletal pain are of little help in patients with fibromyalgia. Thus, nonsteroidal antiinflammatory drugs and corticosteroids have been shown to be generally ineffective (14-16). While narcotics have not been evaluated in controlled trials, clearly they should be avoided in this condition. Local injection of 'trigger' points with either local anesthetics or corticosteroids has been claimed to be effective in patients with myofascial pain. However, no controlled studies are available to support this claim. Such injections cannot be recommended in the treatment of patients with fibromyalgia.

In the absence of pharmacological means to relieve the pain effectively, one has to rely on simple measures such as the use of heat, especially in the form of hot baths which provide temporary pain relief in most patients. Pillows that adequately support the neck during sleep should probably be used, but again there are no solid data to support this recommendation (17). 'Passive physiotherapy' in which antalgic modalities are applied (heat, ultrasound, etc) by a therapist should be avoided since it only helps to promote a sickness role.

\section{SLEEP MANAGEMENT}

The vast majority of patients with fibromyalgia report sleeping poorly and feeling unrested in the morning. It is unclear whether this is due to a primary sleep defect or to the simple effect of chronic pain affecting the quality of sleep. Tricyclic agents such as low dose amitriptyline (10 to $25 \mathrm{mg}$ at bedtime) (18-20) and cyclobenzaprine (10 to $20 \mathrm{mg}$ at bedtime) $(20,21)$ have been shown in controlled trials to improve sleep and fatigue in onethird to one-half of the patients. This clinical benefit, when

\section{TABLE 1}

Follow-up studies of patients with fibromyalgia

\begin{tabular}{lccc}
\hline Study (reference) & $\mathbf{n}$ & Follow-up & \% unchanged or worse \\
Felson et al (5) & 39 & 1 -3 years & $>60$ \\
Ongchi et al (6) & 75 & 3.3 years & 68 \\
Norregaard et al (7) & 83 & 4 years & 71 \\
Ledingham et al (8) & 72 & 4 years & 74 \\
Granges et al (9) & 44 & 2 years & 51 \\
\hline
\end{tabular}

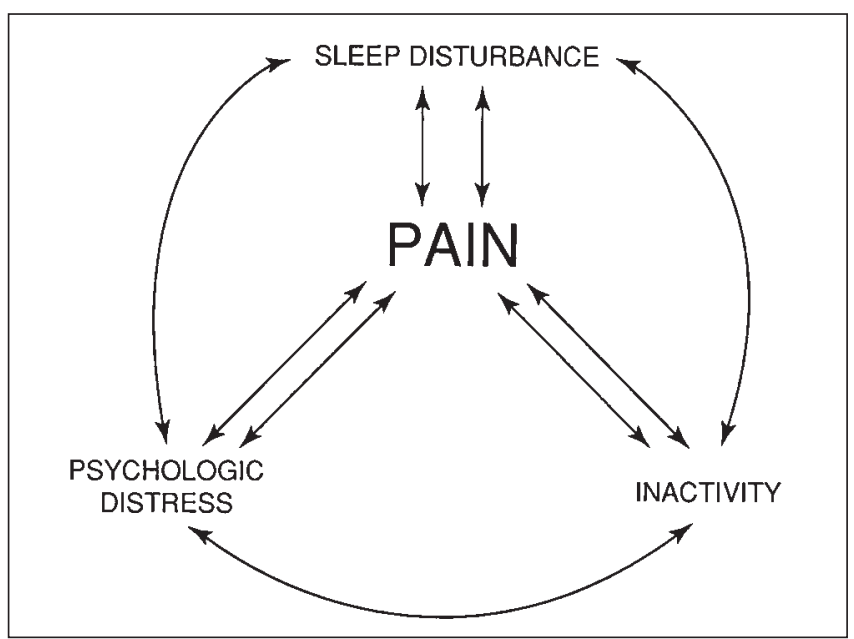

Figure 1) Model of symptom perpetuation in fibromyalgia

present, appears within the first two to four weeks of treatment. The drugs are somewhat less effective in reducing pain than in improving sleep and their long term efficacy has yet to be demonstrated. For these reasons, these drugs remain of limited usefulness in the treatment of patients with fibromyalgia.

\section{PSYCHOLOGIC MANAGEMENT}

In contrast to earlier studies which found few psychological abnormalities in patients with fibromyalgia, most recent studies have shown increased depression and other psychological problems in fibromyalgia patients compared with healthy individuals (3) and rheumatic disease controls (22). Although these abnormalities could result as a consequence of chronic pain (as part of the vicious cycle described above), the higher prevalence of past depression observed in patients with fibromyalgia than in controls $(3,23)$ suggests the possibility of an underlying predisposing psychopathology.

Fluoxetine $20 \mathrm{mg} /$ day was ineffective in a recent six-week, double-blind, placebo controlled trial performed in 42 patients with fibromyalgia (24). Antidepressant doses of amitriptyline or other tricyclic agents have not been formally evaluated, and the role of psychotherapy has not been elucidated. Uncontrolled observations suggest that therapy aimed at helping patients to change their beliefs and behaviour (cognitive-behaviour therapy) may be effective in improving their condition (25-27). While 
these approaches make a lot of sense, it will be important to evaluate them in the context of controlled trials.

\section{MANAGEMENT OF INACTIVITY}

Many patients report aggravation of their symptoms with exercise and consequently reduce their level of activity for fear of exacerbating their condition. This probably explains why most patients are aerobically unfit (28). Recent studies have shown that patients with fibromyalgia can exercise although the benefit of aerobic training in reducing the symptoms of pain and stiffness, and in improving the quality of sleep unfortunately appears to be limited $(29,30)$.

\section{CONCLUSIONS}

It should be quite clear from what has been reviewed so far that there is no magic 'cure' for fibromyalgia. It is essential to get the patient actively involved in his/her management. In recent years, many centres have started to offer multidisciplinary treatment programs that combine most of the approaches described above (education, cognitive and behaviour modification techniques, aerobic exercise, etc). The primary goal of these programs is to educate patients about what they can do to improve their condition (31). Evaluation of such programs is difficult because of the lack of adequate controls. Whether such programs are superior to each component used in a different context (for example as part of a patient-physician relationship) is unknown. The cost of these programs as well as their long term efficacy will have to be evaluated before they become standard practice.

\section{REFERENCES}

1. Wolfe F, Smythe HA, Yunus MB, et al. The American College of Rheumatology 1990 criteria for the classification of fibromyalgia. Arthritis Rheum 1990;33:160-72.

2. Carette S. Fibromyalgia 20 years later: What have we really accomplished? J Rheumatol 1995;22:590-4.

3. Wolfe F, Ross K, Anderson J, Russell IJ, Hebert L. The prevalence and characteristics of fibromyalgia in the general population. Arthritis Rheum 1995;38:19-28.

4. White KP, Speechley M, Harth M, Ostbye T. Fibromyalgia in rheumatology practice: A survey of Canadian rheumatologists. J Rheumatol 1995;22:722-6.

5. Felson DT, Goldenberg DL. The natural history of fibromyalgia. Arthritis Rheum 1986;29:1522-6.

6. Ongchi DR, Dill ER, Katz RS. How often do fibromyalgia patients improve? Arthritis Rheum 1990;33:S136.

7. Norregaard J, Bulow PM, Prescott E, Jacobsen S, DanneskioldSamsoe B. A four-year follow-up study in fibromyalgia. Relationship to chronic fatigue syndrome. Scan J Rheumatol 1993;22:35-8.

8. Ledingham J, Doherty S, Doherty M. Primary fibromyalgia syndrome: an outcome study. Br J Rheumatol 1993;32:139-42.

9. Granges G, Zilko P, Littlejohn GO. Fibromyalgia syndrome:
Assessment of the severity of the condition 2 years after diagnosis. J Rheumatol 1994;21:523-9.

10. Dudley Hart F. Fibrositis (fibromyalgia) - A common non-entity? Drugs 1988;35:320-7.

11. Cohen ML, Quintner JL. Fibromyalgia syndrome - a problem of tautology. Lancet 1993;342:906-9.

12. Horven S, Stiles TC, Holst A, Moen T. HLA antigens in primary fibromyalgia syndrome. J Rheumatol 1992;19:1269-70.

13. Greenfield S, Fitzcharles MA, Esdaile JM. Reactive fibromyalgia syndrome. Arthritis Rheum 1992:35:678-81.

14. Goldenberg DL, Felson DT, Dinerman H. A randomized, controlled trial of amitriptyline and naproxen in the treatment of patients with fibromyalgia. Arthritis Rheum 1986;29:1371-7.

15. Yunus MB, Masi AT, Aldag JC. Short term effects of ibuprofen in primary fibromyalgia syndrome: a double-blind, placebo controlled trial. J Rheumatol 1989;16:527-32.

16. Clark S, Tindall E, Bennett RM. A double blind crossover trial of prednisone versus placebo in the treatment of fibrositis. J Rheumatol 1985;12:980-3.

17. Smythe HA. The C6-7 syndrome - Clinical features and treatment response. J Rheumatol 1994;21:1520-6.

18. Carette S, McCain GA, Bell DA, Fam AG. Evaluation of amitriptyline in primary fibrositis: a double-blind, placebo-controlled study. Arthritis Rheum 1986;29:655-9.

19. Scudds RA, McCain GA, Rollman GB, Harth M. Improvements in pain responsiveness in patients with fibrositis after successful treatment with amitriptyline. J Rheumatol 1989;S19:98-103.

20. Carette S, Bell MJ, Reynolds WJ, et al. Comparison of amitriptyline, cyclobenzaprine, and placebo in the treatment of fibromyalgia: a randomized, double-blind clinical trial. Arthritis Rheum 1994;37:32-40.

21. Bennett RM, Gatter RA, Campbell SM, Andrews RP, Clark SR, Sarola JA. A comparison of cyclobenzaprine and placebo in the management of fibrositis: a double-blind controlled study. Arthritis Rheum 1988;31:1535-42.

22. Hawley DJ, Wolfe F. Depression is not more common in rheumatoid arthritis: a 10 year longitudinal study of 6,608 rheumatic disease patients. J Rheumatol 1993;20:2025-31.

23. Hudson JI, Hudson MS, Pliner LF, Goldenberg DL, Pope HG Jr. Fibromyalgia and major affective disorders: a controlled phenomenology and family history study. Am J Psychiatry 1985;142:441-6.

24. Wolfe F, Cathey MA, Hawley DJ. A double-blind placebo controlled trial of fluoxetine in fibromyalgia. Scan J Rheumatol 1994;23:255-9.

25. Bradley LA. Cognitive-behavioral therapy for primary fibromyalgia. J Rheumatol 1989;S19:131-6.

26. Nielson WR, Walker C, McCain GA. Cognitive-behavioral treatment of fibromyalgia syndrome - Preliminary findings. J Rheumatol 1992;19:98-103.

27. White KP, Nielson WR. Cognitive behavioral treatment of fibromyalgia syndrome: A follow-up assessment. J Rheumatol 1995;22:717-21.

28. Bennett RM, Clark SR, Goldberg L, et al. Aerobic fitness in patients with fibromyalgia: a controlled study of respiratory gas exchange and xenon 133 clearance from exercising muscle. Arthritis Rheum 1989;32:454-60

29. McCain GA, Bell DA. Mai FM, Halliday PE. A controlled study of the effects of a supervised cardiovascular fitness training program on the manifestations of primary fibromyalgia. Arthritis Rheum 1988;31:1135-41

30. Martin L, Edworthy SM, MacIntosh B, Nutting A, Butterwick D, Cook 
J. Is exercise helpful in the treatment of fibromyalgia? Arthritis Rheum 1993;36:S251.

31. Burckhardt CS, Mannerkorpi K, Hedenberg L, Bjelle A. A randomized, controlled trial of education and physical training for women with fibromyalgia. J Rheumatol 1994;21:714-20. 


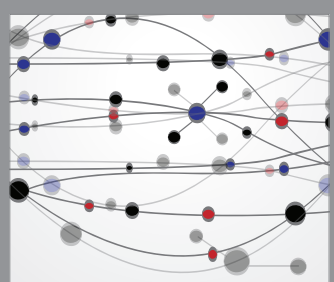

The Scientific World Journal
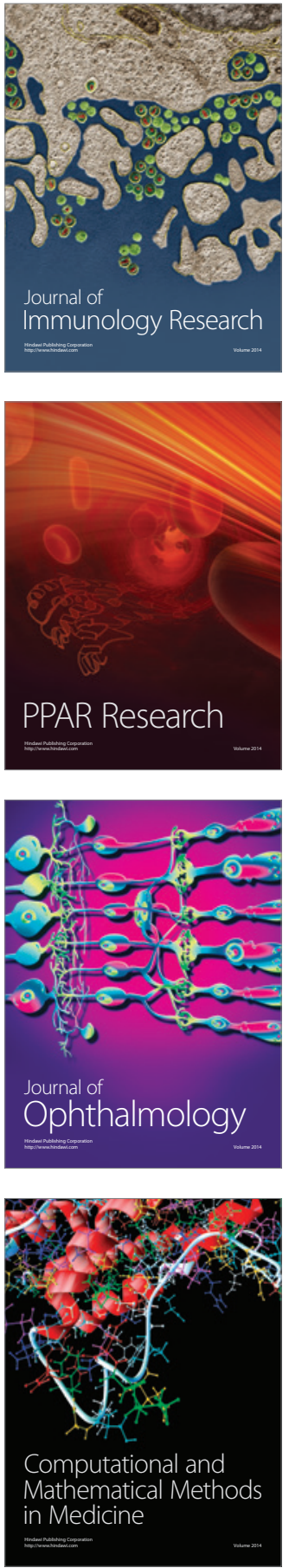

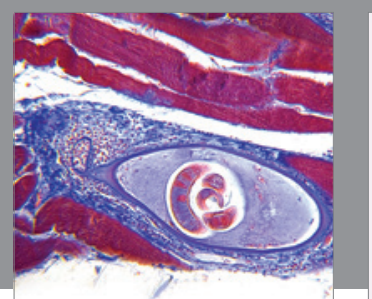

Gastroenterology Research and Practice

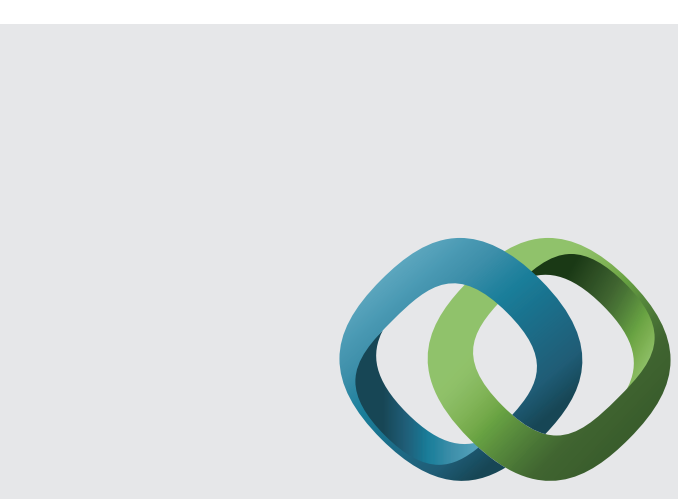

\section{Hindawi}

Submit your manuscripts at

http://www.hindawi.com
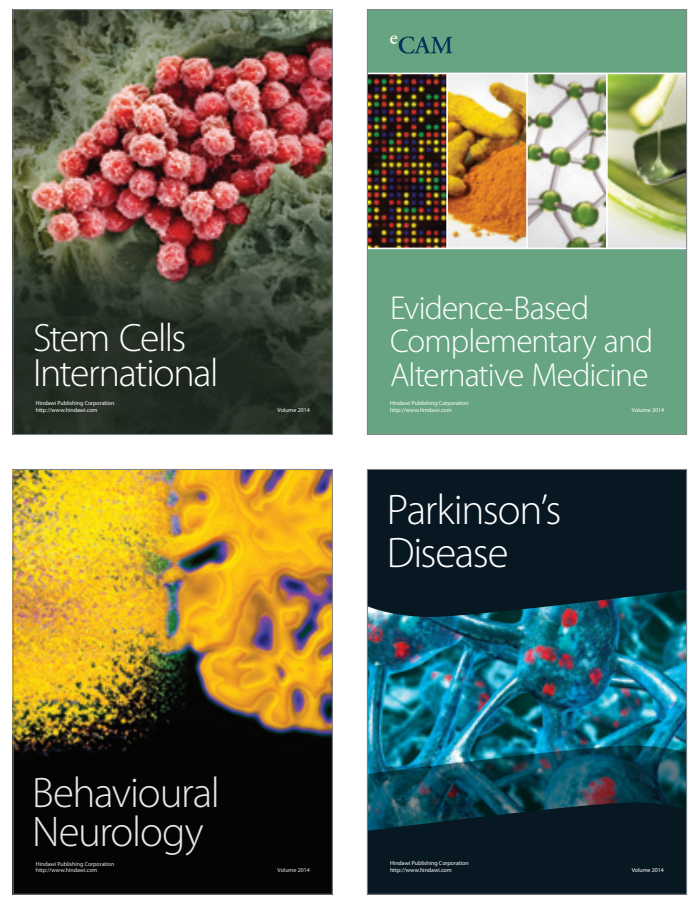
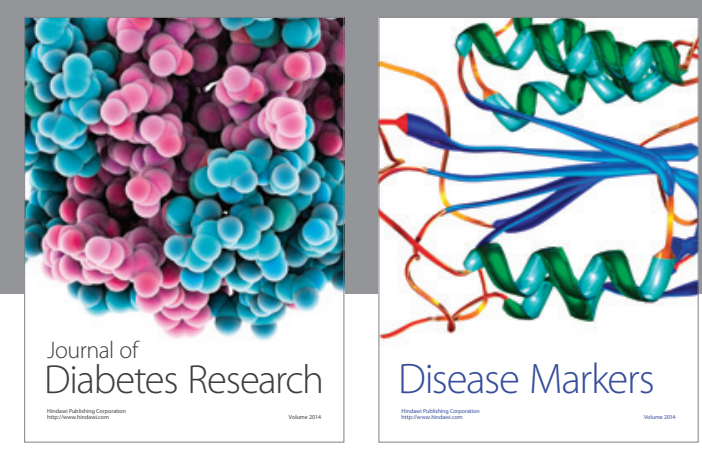

Disease Markers
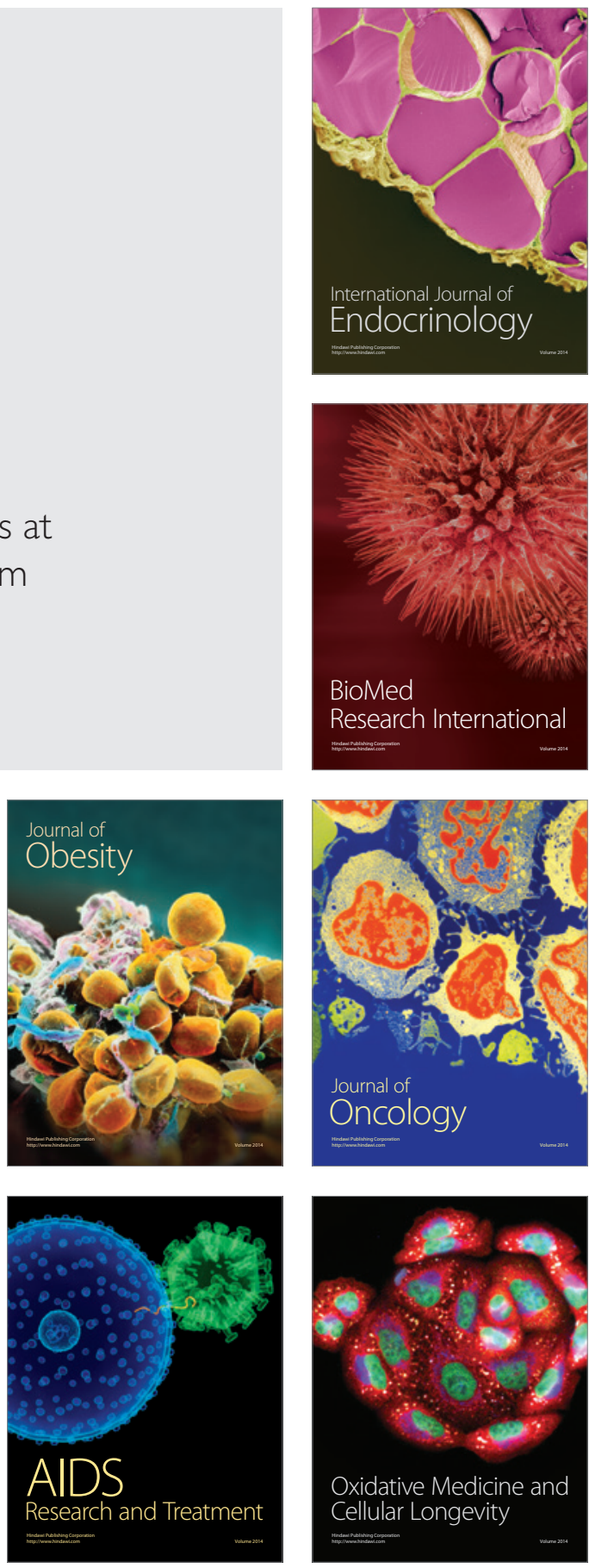